University of Louisville

ThinkIR: The University of Louisville's Institutional Repository

Electronic Theses and Dissertations

1942

\title{
Oxidation of phenanthrene.
}

Frank Hunt Miller

University of Louisville

Follow this and additional works at: https://ir.library.louisville.edu/etd

Part of the Chemical Engineering Commons

\section{Recommended Citation}

Miller, Frank Hunt, "Oxidation of phenanthrene." (1942). Electronic Theses and Dissertations. Paper 1845. https://doi.org/10.18297/etd/1845

This Master's Thesis is brought to you for free and open access by ThinkIR: The University of Louisville's Institutional Repository. It has been accepted for inclusion in Electronic Theses and Dissertations by an authorized administrator of ThinkIR: The University of Louisville's Institutional Repository. This title appears here courtesy of the author, who has retained all other copyrights. For more information, please contact thinkir@louisville.edu. 
$+$

ta:

\author{
ONIVBRSITY OF IOUISVIIIE \\ OXIDATION OF PHENANTHRANE \\ A Thesis \\ Submitted to the Froulty \\ of the Graduate School \\ of the University of Ioulsvilio \\ in Partial Fulfillmant \\ of the Requirements \\ for the Degree of \\ MASTER OF CHMICAI ENGINEBRTIVG \\ Department of Chemfoal Engineering
}

By

Frank Funt Milier, Jr.

1942 
OXIDATION OF PHENANYHR

Frank ifunt lililer, Jr.

Approved by the Bramining Committeo

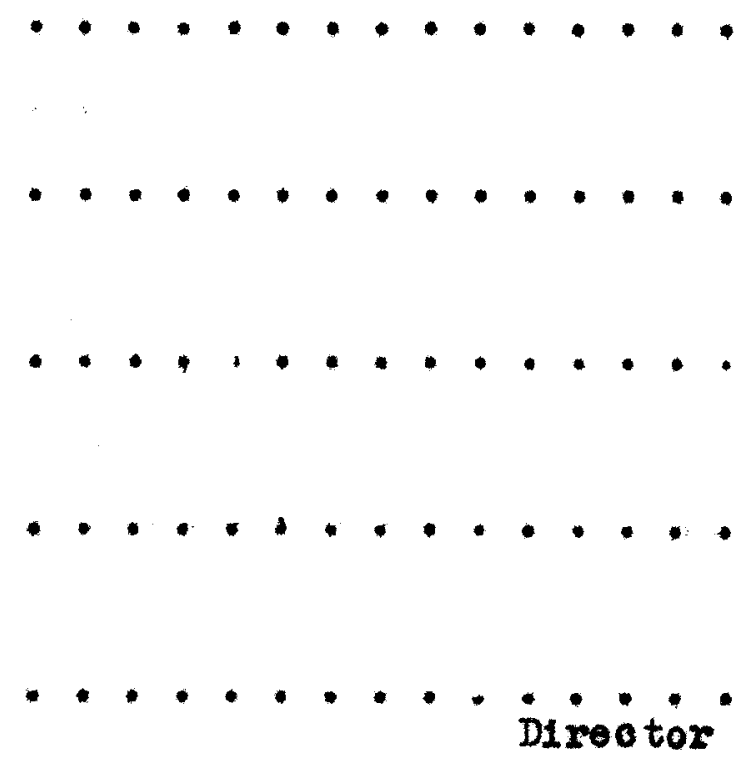

May 15, 1942 


\section{TABTE ON CONTENTS}

Acknow lodgement

Abstreat

Introduotion

H1storloel

3

The ore tioel

8

Experimental

13

Apparatug

14

Procedure

17

Data and Results with Interprotetion 19

Conolusions and Reoommendations 27

Append 1x

29

B1bliography

38

VI ta 
ACYNOWTEDGIMLNT

The author wishes to acknowledge

the kind assistance and holpful

guldance of Dr. Gordon C. Will1ams,

who dirooted this researoh. 


\section{A B S T R A C T}

This investigation was on the oxidation of phenanthrene. The oxidation as attempted by passing unheated atmospherio air through Ilquid phonanthrone, by passing preheated atmospher1o air through 11 quid phenanthreno, and by passing unheated pure oxygen through liquid phenanthrene, varying the temperature of the phenanthrone and using no catalyst.

Only traoss or small yields of the dibasio a.01ds were obtalned in any of the runs that were made. 
IHTRODUCTIOH 
The purpose of this researoh is to investigate the oxidation or phenanthr ne to diphenio acia.

Phenanthrene is one of the many by-products of the destructive distillation of coal. The usefulness of the by-produets of coal carbonization deternines. to some extent, the economio success of the carbonlzation prooess. This investigation was undertaken to increase the eonomio value of phenanthrene.

Whoh research has been and is being carried on to find profitable uses for phenanthrene. However phenanthrene in its original form is of little value and probably will be usable only as a starting materlal that may be changed chemically into more useful chemicals. The prooess that has rocelved the most interest is that of the oxidation of the phenanthrene to diphenic, phthal1o, and malelo acias. The dibasio aoids oan be used by varnish and synthethic resin producers for the mamufacture of various resins. 
HISTORICAL 
The increasing uae of by-produot coke by the metallurgical industries has, in reoent years, oaused the utilization of the by-produats to become more important. In the separation of the constituents of coal tar, phenanthrene is isolated falrly pure and may be considered to be, for practioal purposea, pure phenanthrene.

Discussion will be limited to the processing of phenanthrene to form diphenic aoid, sinoe that reaction was investigated in this researoh. The mechanism of the oxidation of phenanthrene to carbon dioxide and water has been falrly well ostabliahed by many investigetors to be: phenanthrene $\longrightarrow$ phenanthraquinone $\longrightarrow 6,6^{\prime}$ diphenio ao1a $\longrightarrow$ 0-phthal10 ao1d $\longrightarrow$ phenol $\longrightarrow$ malo10 $\mathrm{aO1d} \longrightarrow \mathrm{CO}_{2}+\mathrm{H}_{2} \mathrm{O}$.

The elrat inveatigators to work on phenanthrene oarried out their reactions in a stepwise fashion, in order to disoover the intermediate stops in the totel oxidation to carbon aloxide and weter. The corman chemists of the second half of the last century perforned the reaotions in the ilrst two steps of the total oxidation.

In 1873 phenanthrene was first oxidized to phenanthraquinone by Grabe (7), who oxtalzed purifled phenanthrene with ohromium trioxide in hot acetio acid solution. Iater phenanthrequinone was prepared by Ansohutz and Sohultz (1) In 1879 similarly, using potassium dichroma to and 
sulfurio aoid. These inveatigators mentioned the conoomitant production of some aiphenic acid as the reaction was carriea out. Tater, phenanthraquinone was prepared - leotrolytioally from a suapension of phenanthreno in twonty por cont sulfurio aold using cerium sulfate as a oatalygt by ister. Inolus, and Bruning in 1902, (10).

Mphenic aotd was prepared from phenanthraquinone Pirst by Fittig and ostermayer (4) in 1873 aocording to the following procedure: a solntion of phenanthrequinono in sulfurio aold is poured slowly into a solution of potassium dichromate in water. The heat of dilution of the sulfuric acid is sufficient to start the oxidation and the reaction is completed by refluxing for four hours. The acid is extracted from the precipitate with sodium oarbonate solution. Th1s was repeated by sohmitz (12) in 1878, by Graebe and Aubin (8) in 1888, and by Gotz (6) in 1902. Diphenlo aold also was obtained by bolling phenanthrequinone with aqueous and alcoholie potash by Anschutz and Sohultz (1) in 1879 and the experiment was repeated by Heyer and spengler in 1905 (11).

The research of Gibbs and Conover (5), which in 1918 resulted in a process for the manufeoture of phthelio anhyaride, and in whioh vaporizod napthalene was nixed with air and passed over a heated oatalyst, led to the later process 
disooverod by Low1s and Gibbs (9) for the manufacture of phenanthraquinone by raporizing the phenanthrene, mixing it with air and passing the mixture over a heated oatalyst. The petent they obtained on this latter process in 1918 was assigned to the publio.

In 1922 Gbbs obtainad another patent, U, S. Patent No. $1,444,068$, on a prooess for the oxidation of mixtures of anthracene and phenanthrene, such as may be obtained by the removal of carbazol by cauatic fugion fron anthraceno press eake. Th1s patent claimed the production of phthalio anhydride and anthrequinone when the vapors of phenanthrene and anthracene were mixed with oxygen and passed over the oxddes of ranadium, molybdemum, or chromium. Gibbs assigned it to E. I. dupont de Nemours and Company, W1 imington, Delaware.

In 1937 In. S. Zal'kind and V. V. Kesarev (13) published the sults of an extensive search inquiring Into the rapor phase oxiaation of phenanthrene by air in the presenoe of solid oatalysts. Their best results, 4l per cent mixed dphento and phthalio acids, were obtained when the reaction chamber was held at $390^{\circ} \mathrm{C}$., the catalyst contact tine was four seconds and the phenenthrene supplied to the reaction chamber was at $220^{\circ} \mathrm{C}$. The catalyst masa usod in this instanoe was 70 per sent ranadium oxido and 30 per cent uranium oxide fixed on pumice. 
At about the same tine Chowdbury and Saboor (3) were carxying on similar researohes on the vapor phase oridation of napthalene and phonanthrene with air in the presenoe of tin and vanadium catalysts. Their best yield was 22.35 per cent phthal10 anhydride on oxidation of phenanthrene mixed with alr over tin vanadato - asbestos catalygt at $420^{\circ} \mathrm{C}$.

In 1939 and 1940 Bracken (2) attempted the oxidation of phenenthrene dissolved in benzene using soluble catelysta wh the at room temperature. He found that benzene oxdalzed preferentially and obtained no oxidation of phenanthrene.

The most promising of these processes on a commere1al scale is the oftalytio vapor phase oxidation. The yielda, howerer, are not entirely satisfactory, and this process ontalls some difficulties sinoe high temperatures must be used on aocount of the high bolling points of phenanthrene and the end produota. 
THEORTTCEI 
The oxidation of phenanthrene has been acoomplished by many investigators, as has been mentioned previously. The mochanlam for the stopwise oxidation, as elrst proposed by Chowdbury and saboor (3) is as follows:<smiles>C1CCC2C(C1)CCC1CCCCC12</smiles>

Phenanthrene<smiles>O=C1C(=O)C2CCCCC2C2CCCCC12</smiles>

Phenanthraquinone
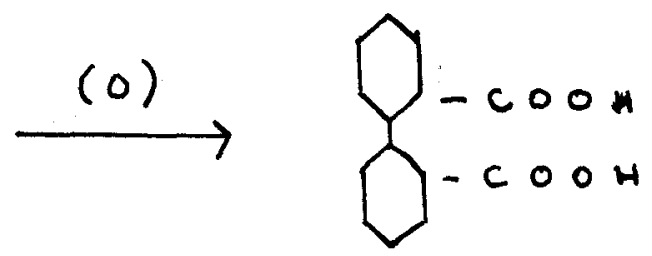<smiles>CCC(C)COC(=O)C=CC=CC(=O)O</smiles>

It is seen from this reaction that there aro two useful derivatives, diphenic acid and phthalic acid, both of whioh are used in the synthetio reain industry.

The addition of oxygen to a moleoule to break 1t Into oxidized parts or to make an oxidizod moleoule mast be performed by an oxidizing agent. The number of possible oxidizing agents is greatly lind ted beoause the agent to be used mast be relatively cheap, and it must be soluble, unless it is a gas, in liquid phenanthrene or in a solution of phenanthrene in one of its solvents. By far the cheapeat oxidizing agent is alr. It was deolded to use, if possible, air for the oxidizing agent. 
The adrantage of agents other than molecular oxygen, such as is in a1r, is that the agents themselves are relleved of their oxygen, releaging it in the atomic state, which state is much more reactive than the molooular state. The use of a oatalyst wh tholecular axygen, however, decreases this advantage, since the catalyst is considered. to oonvert nolecular oxygen to the atomio or "nasoent" s tate. It may be nocossary, if the alr $1 \mathrm{~s}$ used for the oxidizing agent, to use a catalyst.

There are two factors to be considered in the problem, equilibrium and reaotion rate. The oxidizing agent and reaction conditions must be such that a favorable equilibrium is reahed, and that the reation rate causes this equilibrium to be reached in a reasonable time. The use of the proper oatalyat, while not affocting the final -quilibrium, will inorease the reaction rato.

The oxidation may be accomplished in the 11 quid ate or the vapor state. Oxidation in the liquid state may be performed by bubbling air throush liquid phenanthrene or through phonanthrene dissolved by a suitable solvent, if the solvent is stable with respect to the oxidizing effoct of the air being bubbled through. oxidation in the vepor state 1s done by blowing heated gas (either alr or oxygen) through meltad phenenthrene, to pick up phenanthrene vapor and passing the hot mixture of gas and vapor through a heated ostalyst mass. The vapor state reaction is sometimes 
carried out in a pressure chamber, using a batoh process instead of the above described continuous process. In the latter process solld phenanthrene is put into the reation vessel, the oxidizing gas is added under pressure, and the vegsel is heated to a temperature that will melt the phenanthrene and vaporize a conalderable portion of 1 t. If a oatalyst is to be used it is added with the phenanthrene. 11 a golla or liquid at room temperature, or added with the oxidizing gas if a gas at room te perature. of the above methods of oxidati on of phonenthrene only the continuous rapor ste to process usin successfully aooomplished. This was done by zel'kind and Kesarev (13) and Chowdbury and Saboor (3), the former obtaining a yleld of 41 per oent mixed diphenic and phthalio aoids, and the latter obtaining 22.35 per cent phthalio anhydride (probably finding and not roporting some diphenio acia). No succesaful oxidations have been acoomplished by passing air through melted phenanthrene or a phenanthrene solution.

Pollowing a line of increasingly costly methoda the progression is as follows:

1. Bubbling unhes ted air through melted phenanthrene.

2. Passing preheated air through melted phenanthrene.

3. Continuous repor phase processes. 
4. Passing unhoatod air through phonanthrene in solution with a non-oxidizable solvent.

5. Passing heatod air through phonanthrene in solution with a non-oxidizabie solvent.

$6 ., 7 ., 8 ., 9, .10$. The ge game prooesses, in whioh pure oxygen is substituted for a1r.

11. Bubbling oxidizing agents other than air or oxygen through melted phenenthrene.

12. Continuoug rapor phese processes in whioh volatile oxidizing agentg other than a1r or oxygen are used.

This progression may not hold true, however, in a case where a hich yleld in a relatively costly prooess would make the undt oost on the meterial produced lower than a leas costly prooegs in whioh the yiela is low. Since it had been already established by both Zal'kind and Kesarev, and Chowdbury end Saboor that phenanthrene oan be oxidized by air, it wes declded to attempt to oxidize phenanthrene by meling 1 t and passing air through 1t; then, if the yield on this prooedure was not high enough to make the unit oost on the material produoed lower than the unit cost using the oontinuous rapor phase process, to prooeed to the next wore oostly prooess, and so on. 
SXPIRTMETLI 
APPARATUS

The apparatus used for the experimental work consisted of a large glass test tube (one inoh in diameter and elght inches in length), whioh was the reaotion chamber; a mood's metal bath around the teat tabe; and a stopper for the tube whioh ontalned three holes, one for the entranoe of the oxidizing gas, one for a $360^{\circ} \mathrm{C}$. thermometer, and one for the extt of reacted gas. The reacted ges was conduoted from the reaction tube to a large alr aondenser which was a pleoe of glass tubing three quarters of an inch in alameter and elghteon inches in length.

For the various kinds of experimental rung there were vartous kinds of auxiliary equipment attaohed to the above reation tube and condenser. Then the oxidizing gas was a troapheric a1r, unpreheated, there was a vacuum aspirator comnectod to the oxit ond of the air condenser. During the run in which proheated atmospher10 gea was used as the oxidizing agent, there was a small coil of oopper tubing (outside diameter three sixteenths of an inoh) attached to the oxidizing gag entranoe of the reaction tube. On this mun also a racuum aspirator oonneoted to the ext gide of the afr condenser.

then unpreheated oxygen was used as the oxtdizing gas the oxygen was blown through the reaction tube from a high preasure oxygen storage tank and the vacuum 
aspirator was not used.

A sketoh of the above desor1bed apparatus appears on the following page. 


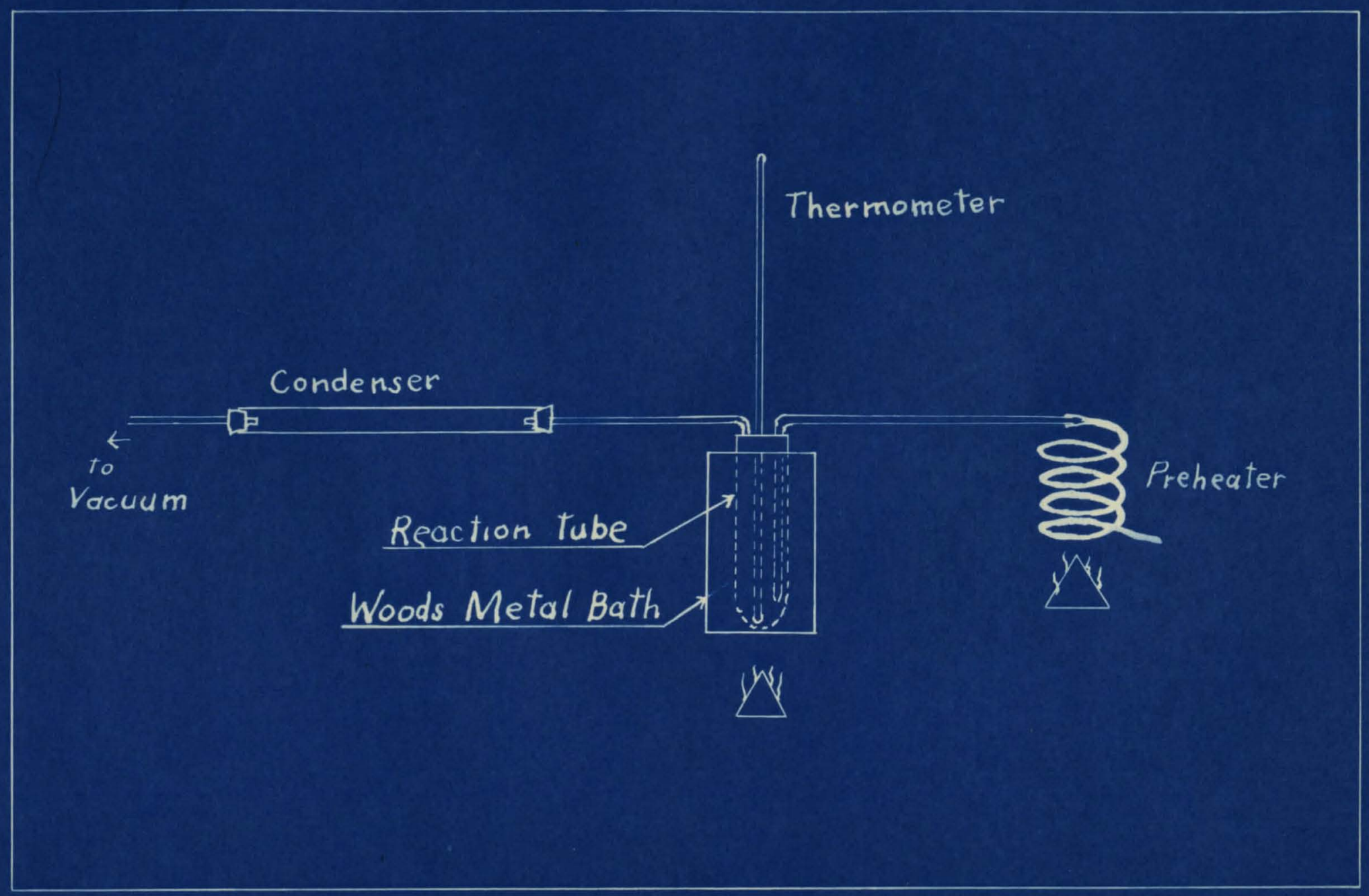

EXPERIMENTAL APPARATUS

FIG. I 
PROCEDURT

The experimental reactions to produce alphenio aold from phonanthrene were prooeded by some preliminary tests to aet up a method of analysig of reacted mixtures.

The method used by Braoken (2) was adoptod with changes necessitated by a diference in the material to be analysed. The procedure was as follows: The reacted material was in two paxta, the material which remainoa in the reaction tube at the end of the run, and the material Which had been carried from the reaction tube to the air ondenger, olther by belng raporized in the reaction tube and ondensed in the condenser or by being entrained in the gas that was being bubbled through the phenanthrene In the reaction tube.

These two reacted masses were, o1 ther separately or together. macerated with a standard water solution of sodium hydroxide et the bolling temperature of tho solution, The water soluble acids, alphonic, phthalic, end meleio. were thereby extxaoted from the water ingoluble materiala, phonanthrene and phenanthraquinone by forming the lonized sodium alt and water with the sodium hydroxide. The reations are:

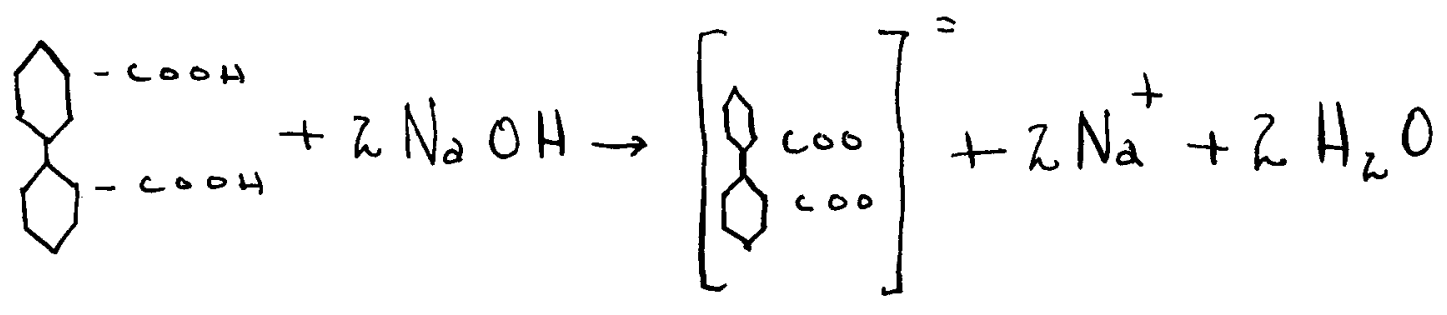




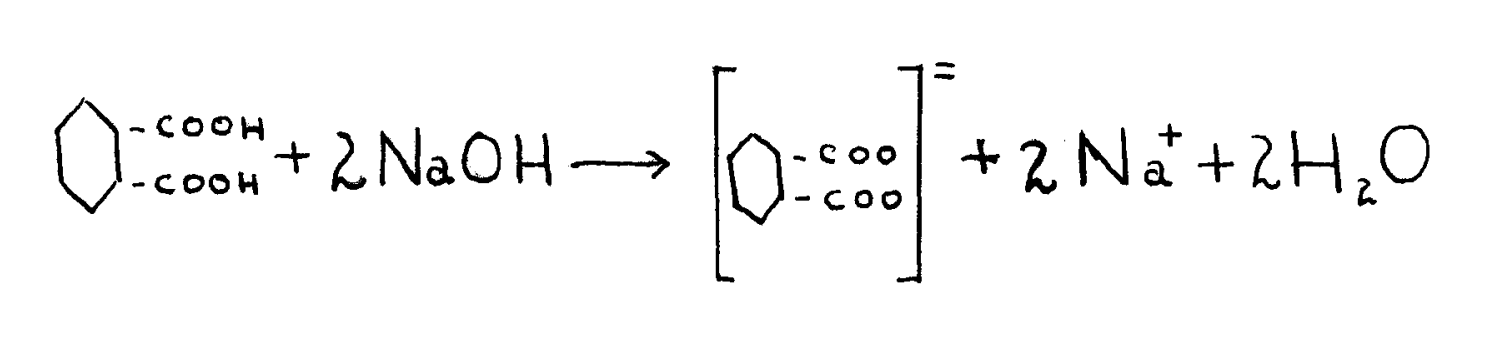<smiles>CC(CCC=CC(=O)O)C(=O)ON=O</smiles>

The water solution of sodiun hydroxide contained an amount of sodium hydroxide in excess of the amount necesary to react with the ataount of acids preant. The exoesa sodium hydroxide was titrated with stindardizod sulfuric aold after the extraotion was made. The percentage oonvorsion of the phenanthrene was calculated from the amounts of sodium hydroxide and sulfurte acto used. The testing of the anelytical prooedure, blank runs, and verious oxidation trials wero so detalled and varied that they will be disoussed seperately under "Data and Resulta." 
DATA AND RESUITS 
The Test Analyses

Ran 1. (Blank) Twenty-11 ro g. phenanthrene wa boilod ath $\mathrm{H}_{2} \mathrm{O}$ for 15 minutes. Supernatant water was titrated with 1.037 normal FaOH while still in oontact with the 11quid phonenthrone. The phenolphthalein ond point was lesa than .01 ml.

Run 2. Two Erams phthalic anhydride and $25 \mathrm{~g}$. phenanthrene were melted together and then boiled for 16 minutes with $250 \mathrm{ml}$. $\mathrm{H}_{2} \mathrm{O}$. The supernatant water was titrated with 2.037 normal NaOH while still in oonteot with the liquid phenanthrene using phenolphtholein 1ndioator. Pink oolor appeared permanently at $26.5 \mathrm{ml}$. Equivalent wt. phthel10 anhydride $-\frac{148.11}{2}=74.06 \mathrm{~g}$. Bquivalents phthal1e antydride used $=\frac{2}{74.06}=.0270$ Bquivalents shown to be preaent by toat $=\frac{1.037 \times 26.5}{1000} \cdot .0275$ Result: The amount of phthalic anhydride present was disoovered with an cocuraoy within the linit of experimental error.

Hax 3. The manufacture of phonanthraquinone from phonanthreno as a done by Graebe (7). Two hundred twenty-117e $\mathrm{g} \cdot \mathrm{H}_{2} \mathrm{SO}_{4}(\mathrm{sp} \cdot \mathrm{gr} \cdot 1.84)$ was plaoed in a $1000 \mathrm{ml}$. Nlorence flask with $300 \mathrm{ml} . \mathrm{H}_{2} 0$. 
Seventy-five $8 . \mathrm{KCr}_{2} \mathrm{O}_{7}$ was added to the llask and dssolved. Brenty-flve $z$. orude phenanthrene $190 \%$ phenanthrene, $10 \%$ anthracene, trace carbazole) was placed in the elaak and the mixture wa heated gently with a rellux condenser atteched to the top of the Plagk. Seventy-11ve grams $\mathrm{K}_{2} \mathrm{Cr}_{2} \mathrm{O}_{7}$ was added to the mixture and bolled for one hour. The mixture was cooled and placed in two $1500 \mathrm{ml}$. beakers, half in oaoh beaker. The beakers were filled with water and the aquo ous mixture wa filtered in an attempt to retain the orystallizod phenanthraquinone on the I1Iter paper. Several largo lunps of what appeared to be unreacted phonanthrene remainod in the bottoms of the beakers. The regldue wes orushed while st1ll wet and pleoed in a $400 \mathrm{ml}$. beaker. $\mathrm{H}_{2} \mathrm{SO}_{4}(\mathrm{sp} \cdot \mathrm{gr} \cdot 1.84)$ was poured into the beaker until it covered the wet solld and the mixture was allowed to stand for 48 hours.

The aold wes diluted by adding water to the beaker in the ratio of (water to acid) 10 to 1 . Then the acid was poured off and the residue washed with 1 nomel NaOH and with water. The residue from this wash was digested with sodium bigulit te solution in which phenanthraquinone is soluble and anthraquinone insoluble. The digestion was Iiltorod into a filter Plask containing a solution of dil. $\mathrm{H}_{2} \mathrm{SO}_{4}$ and $\mathrm{K}_{2} \mathrm{Cr}_{2} \mathrm{O}_{7}$. A procipitate appeared inside the 
iliter flask. The residue wes rejeoted. The prooipitate contained in the contents of the iliter llask was ooggulated by the addition of a mall amount of conc. $\mathrm{H}_{2} \mathrm{SO}_{4}$ and ilitered agein. The residue was dried (riltrate rejected), alssolved in ther, filtered (rogidue rejected), and the filtrate avaporeted on a vatoh glass. The melting point of tho crystallized solld was determined to be $160-165^{\circ} \mathrm{C}$. With a hoated stege melting point apparatus.

A small part of the phenanthraçuinone was placed in a tost to with .2 g. powdered zino and $5 \mathrm{ml}$. of . I nommal Hath. Th1s nixture was bolied for 30 seconds and Piltered while hot. If anthraquinone had been present the Iil trate would have been deep red. The fil trate was pale yollow. Th1s wa a negative qualitative tost. A small amount of the phenanthraquinone was plaoed in a test tube and $5 \mathrm{ml}$. $\mathrm{H}_{2} \mathrm{SO}_{4}$ (ap. Br. 2.84) added. A deep green oolor indlosted the positive presenoe of phenenthrequinone.

4.2 6. anple of the product was placed in ether solution and was titrated with . I normal irom. The end polnt wes at $1 \mathrm{ml}$. This indicated an incomple to removal of sulfurio aota.

Run 4. A bixtare of phenanthrene, phenanthraquinone (prepared in the laboratory), and diphenio acld wes made up in the following proportions: 


$\begin{array}{ll}\text { Phenanthrene } & 6.00 \mathrm{~g} . \\ \text { Phenanthraquinone } & 4.09 \mathrm{~g} . \\ \text { Diphenle Aold } & 2.00 \mathrm{~g} .\end{array}$

This mixture was placed in a ocsserole, melted, and the reacted mixture analyals performed on it. The acid extraction with sodium hydroxide solution and back titration of the solution showed the presenoe of $2.83 \mathrm{~g}$. of diphenie ao1d. Extraction of the phenanthraquinone from the phenanthrene with sodium bisulfite solution as in the preoeding mun yiolded $1.14 \mathrm{~g}$. phenanthraquinone. the remaining phonanthreno weighod $6.77 \mathrm{~g}$.

The diphenic acid result was high because of insufflolent removal of the aold fram the phonanthraquinone. The phenanthraquinone contained enough sulfurio aoid to show a test for $.0481 \mathrm{~g}$. of diphenic acid. The error in the a1phento a.old determination above $.0481 \mathrm{~g}$. may be acoounted for in the exporimental work. The phenanthrene value was probably high and the phenanthraquinone wa:s low because of ineomplete extraction of phenanthrequinone from the phenanthreno by sodium bialif te solution.

Bxperimental Rans

Approximately $20 \mathrm{~g}$. phenanthrene was plaoed in each of six large pyrex test tubes. An 011 bath was made of $1000 \mathrm{ml}$. beaker and cottonseed oil, with a thermometer saspended in the 011. Baoh of the tubes wes plaoed in the 
011 bath and heated at an elevated temperature for a short titne, while air was passed through the liquid phenanthrene. At the end of the hesting period the phenanthrene was dumped into a casserole oovered with $100 \mathrm{ml}$. Aistilied $\mathrm{H}_{2} \mathrm{O}$, and titrated with .107 normel $\mathrm{NeOH}$ and phonolphthale in at $100^{\circ} \mathrm{C}$. to determine acid content of the phenanthrene. All the data are on the following tables. The amounts of aolds were so small that a dreot titration with NaOH was setisfactory.

Date:

Run Dt. Phenanthreno Reaction mine Reciotion jemp. corsoH

$\begin{array}{lllll}5 & 21.11 \mathrm{g*} & 35 \mathrm{~min} . & 200^{\circ} \mathrm{c} . & 0.35 \\ 6 & 22.00 \mathrm{~g} * & 45 & 225^{\circ} \mathrm{C} . & 0.35 \\ 7 & 25.89 \mathrm{g*} & 40 & 250^{\circ} \mathrm{C} . & 0.35 \\ 8 & 21.50 \mathrm{g*} \cdot & 45 & 275^{\circ} \mathrm{c} . & 0.55 \\ 9 & 23.01 \mathrm{g*} & 45 & 300^{\circ} \mathrm{C} . & 0.50 \\ 10 & 34.75 \mathrm{g*} & 45 & 325^{\circ} \mathrm{C} . & 0.35\end{array}$

Twenty g. of phenanthrene tha titrated as a blank and 0.35 oc. of haot was uged. Result: Only traces of the nlxod acids were forned. The apparatus shom in the sketoh on page 16 was assembled and 11 quid phenanthrene was treated by pasalag preheated atmospheric air through it. The sodium hydroxide 
extraotion method was used to analyze the reacted mixtures. Bromthymol blue was used from this point on as an indieator. Data :

Pan Regotion Time Reaction Temp. \&yleld mixed golds

$112 \mathrm{hr} .0 \mathrm{~min} .280-325^{\circ} \mathrm{C} . \quad 0.054$

$122 \mathrm{hr} .30 \mathrm{~min}$. $280-320^{\circ} \mathrm{C}$. 0.0258

$131 \mathrm{hr} .0 \mathrm{~min} . \quad 280 \odot 320^{\circ} \mathrm{C}$. 0.059

$141 \mathrm{hr} .50 \mathrm{~min} . \quad 305-315^{\circ} \mathrm{C} . \quad 0.062$

$151 \mathrm{hr}, 0 \mathrm{~min} . \quad 310-320^{\circ} \mathrm{c} . \quad 0.080$

The tenperature of the preheated air was not determined. The length of the preheated tube was 3.5 feet, and it was hoated to a bright red color in oach of the above runs.

The apparatus shown in the sketch on page 16 was changed In that the preheater removed and a line to a compressed oxygen tank was substituted in its place. The suotion aspletor was disoonnected. The gases coming from the air condenger woro bubblod through a small beaker of distilled water before being exhausted to the atmosphere. Both the weter in this beaker and the reacted mass in the reaction tube wore analyzod for mixed aolds in reporting the peroent yield. The oxygen was not preheated.

Data:

Run Reaction Tize Reaction Tenp. BYold Mixod hoids

1 hour

$245^{\circ} \mathrm{C}$. 0.146 
Run Reaotion Pime Reaction Term. \& Yield Mixod Aolda

17

1 hour $265^{\circ} \mathrm{C}$.

0.276

18

1 hour

$300-310^{\circ} \mathrm{c}$.

0.302 
CONCLUSIONS AND RICOMARTDATIUNS 
The oxidation of phenanthreno to nixed diphenio, phthalio and maleio acids by pasaing atmospherio alr, both unpreheatod and preheated, and plire oxygen, unprehoa tod, through molted phenanthrene at rarious temperatures produced only treces of the mixed ac1ds.

It is recommended that subsequent investigationa continue as follows:

1. Use of preheated oxygen.

2. Use of a1r and oxygen heated and under pressure.

3. Uge of a non-oxiatzable carrier for liguld phase oxidization.

4. Use of catalyatg for most proming of previous experiments. 
APPEDIX 
In adition to the profect reported in the proceding sections of this thesis the author spent oonsiderable laboratory time in working on three other projects of the Diviaion of Indiatrial Researoh. The following are ahort reporta of the nature of his work on the projects.

1. The Refining of Cadmium from Waste Ore.

The problem involved the rolaiming of cadmium from an indugtrial wast material of unknown source. The analyg1s of this waste ore showed the following:

$\begin{array}{lr}\text { Cadmium } & 80 \% \\ \text { Arsento } & 16 \% \\ \text { Ioad } & 4 \%\end{array}$

The intial separation was a digestion with dilute suliurlo ac1d. The sulfate of lead is quite 1nsoluble. It but on analysis it was found that arsenio was dissolved by the dil. $\mathrm{H}_{2} \mathrm{SO}_{4}$ alao. The amoint of the oristnal material that went into golution wag found by using a goooh orvoible. The investigation was continued, using the dilute $\mathrm{H}_{2} \mathrm{SO}_{4}$ to dissolve the arsenio and cadmium. Then the removal of the arsenic wa attempted by adding ferrou sulfate crystals, allowing them to $g 0$ into solution, and adding hot inlk-of-lime suspension to the acid solution until the solution became basio, in an effort to cause 
oopreolpitation of the arsenic. This method was suooesaful in removing the arsenic from solution but also removed all but treoes of the cadmium.

The method of attack was then ohanged. The sol1d material wag treated with a mixture of concentrated nitric and hydrochlorio aolds. The chloride of load in insoluble, for praotioal purposes. The resulting solution of arsento and oadmium chlorides was then evaporated to dryness and heated at $150^{\circ}$ C. Por severel minutes. The chloride of trivalent arsenio 1a a liquid at room temperature and bolls at about $130^{\circ} \mathrm{C}$. It was hoped that the a rsenic would be converted to the triohloride and be vaporized at $130^{\circ}$ c. This would leave only a residue of cadmium chlorido. This approach failed, probably beoause there was pentavalent argenio present in the original material.

The investigation here was disoontinued, because the raw material was taken off the market.

2. The Utilization of rood Vaate for a Plast1c. This projeot was an investigation of the possibility of using a wood waste in the form of sewdust and sander dust as a plagtio forming material or as an extender or diluent in a standard moulding compound.

The equipment used to marafaoture test pellets that were made for experimental purposes was a standard laboratory hydraulle press of 5000 pounds per square inch 
capaofty when used with a 1 inch (inside dianeter) molding-die. The die was a standard 1 inch inglde diame ter 1.5 inoh outaide diameter, metallurgical specinen mounting die.

The molding procodure was as follows: The mixture was placod in the die and the hoating oloment placod around the die with the current on. The two pere plaoed In a laboratory press, a thermometer being put into the top of the d10, in a well, through the press frame, a hole having been made in the press frame for this purpose. The pressure on the die was adjusted to $2000 \mathrm{p} . \mathrm{s.1}$. (pounds pex square inch) and held there. When the thermometer, whloh rose slowly from room temperature, reached $100^{\circ} \mathrm{C}$. the current was turned off in the heating element, and the element was allowed to stay around the die for 5 rainutea while the pressure was $2000 \mathrm{p} . \mathrm{g.1}$. At this time the pressure was released and the heating element was qulokly replaced by a water cooled oooling element. When the temperature reached $55^{\circ}$ C. (the press was held at $2000 \mathrm{p} \cdot \mathrm{s.1}$. during the oooling period) the pressure was released, the die taken apart and the pollet removed. Pollets were made of the following mixtures:

Mumber $A-1$ A-10 Partg inaterial

$5(g *)$ dry sander dust

$$
5
$$

n
Parts Matorial

I

2 n 
Tumber

Parts Matorial

Parta Matorial

$A-3$

$5(8$.$) ary sander dust 3$ (g.) urea

A-2 5

" $"$

$2 \frac{1}{2}$

f)

$A-11$

5

$n n$

n

4

n

A-4

10 (g.) wet sawdust green 1

A-5

10

$n$

i

3

A-6

10

n

n

4

$A-7$

10

$n$

it

5

n

A-8

5

Ary sander dust

5 urea $+0.2 \mathrm{NH}_{4} \mathrm{Cl}$

A-9

5

"

$n$ "

1

urea

$A-12$

10

wet sawaust groon 2

$n$

A-13

10

$n n$

1" 6

n

$A D-1$

10

$A D-2$

10

dry sander dust

$1(8$.

$*$

$A D-3$

10

"

$\pi$

2

n

$A D-4$

10

n $n$

3

n

n $n$

4

n

In the mtxtures, number A-1, A-2, to., on the procoding ohart the mixtures were made and onough water addea to make a paste. Th1s paste wa well mixed and then arled for three to four hours in an oven at $95-100^{\circ} \mathrm{C}$. The pellets were then made from the arted material.

In the mixtures numbered $A D-1, A D-2$, eto., the sander dugt was mixed in the dry state with the urea and the pellets made from this ary material. 
A group of gamples of wet sawdust, Chestnut or Rook Cak, Hlokory, Red Oak, Beooh, Chestnut, Yellow Poplar, Hard iaple, Soft Haple, Blrch, and Red Dak (urea treated), were analyzed for molature content and pellets were made of the group, one peilet of oach speote. The proportions were onough wet sawdust to make five grams dry and two and a helf grams of urea. Enough water was added to this nixture to make a paste, and the mixtare was dried in a $100^{\circ} \mathrm{C}$. oven, after thorough mixing. The game prodedure we uged in making the $3 \theta$ pellets as was uged before.

There were next prepared saturated solutions of the following salts: $\mathrm{MgCl}_{2} 6 \mathrm{HgO}_{2} \mathrm{MnCl}_{2} 4 \mathrm{H}_{2} \mathrm{O}, \mathrm{NaCl}$, and $\mathrm{BaCl}_{2} 2 \mathrm{H}_{2} \mathrm{O}$. These solutiong are in equilibrium with alr of the following relative mulaltios, respectively: $32.3 \%, 52.4 \%, 76.1 \%$, 89.9\%, when the air over them is allowed to come into equilibrium with the solution.

The solutions were placed in the bottoms of empty reagent jars and two-hole number 10 stoppers, with one gless tube extending through the top to below the surface of the solution and one glass tube extending to the spaoe above the solution, wero plaoe in series so that alr might be drawn through each jar in series bubbling through each alution in sucoession. A jar containing pure water was added to the series. A small wire cage was flxed to the 
under aide of the atopper in each jar and two pellets, one ooated with parafin and one not coated were placed in the oage in each jar. The pellet were of the same oomposition as number A-2. The dimensions, diameter and thicknoss, of each pellet were meaaured with a miorometer and recorded. The object of this experiment was to find out whether the pellets undergo any ohange in dimensions after exposure to air of varying molsture content.

At this point the author stopped work on this projeot.

3. The Design of the Hoating Mlement for a High Pressure Bomb.

A high pressure reaction unit hed been constructed for use in the researoh on the oxidation of phenanthrene. The completion of the unit required the desian of some mothod of heating the high pressure reaction chamber. It was deolded to wrap the bomb casing (see sketoh on page 37). Whioh holds the bomb while it is in use, with a sheet of mica for Insulation and then wrap a length of eleotrio heating element ribbon around the mioa sheeting. The ribbon shall be standard chromel vire ribbon. After prelininnry caloulations it was deolded, with the help of the oatalogae of the Hoskins kfinufacturing Company of Detrolt, Mlohigan, to uge two lengthe of ribbon oach 12 
Ioot in length. The two lengths are to be connected in parallel.

The ribbon is to hold the mica in place and another layer of mioa is to be wrapped around the ribbon to hold the ribbon in place. The outside zayer of mica may be held on by mrapping ordinary beling wire around It and twisting the ends together or by using automobile redietor hose connoctors. Leter the second layer of mia is firmly in plaoe the remaining space in the bomb oasing Is to be Illled with asbestos ilbers to insulate the heating unit from the outside surpace of the bomb assing. 

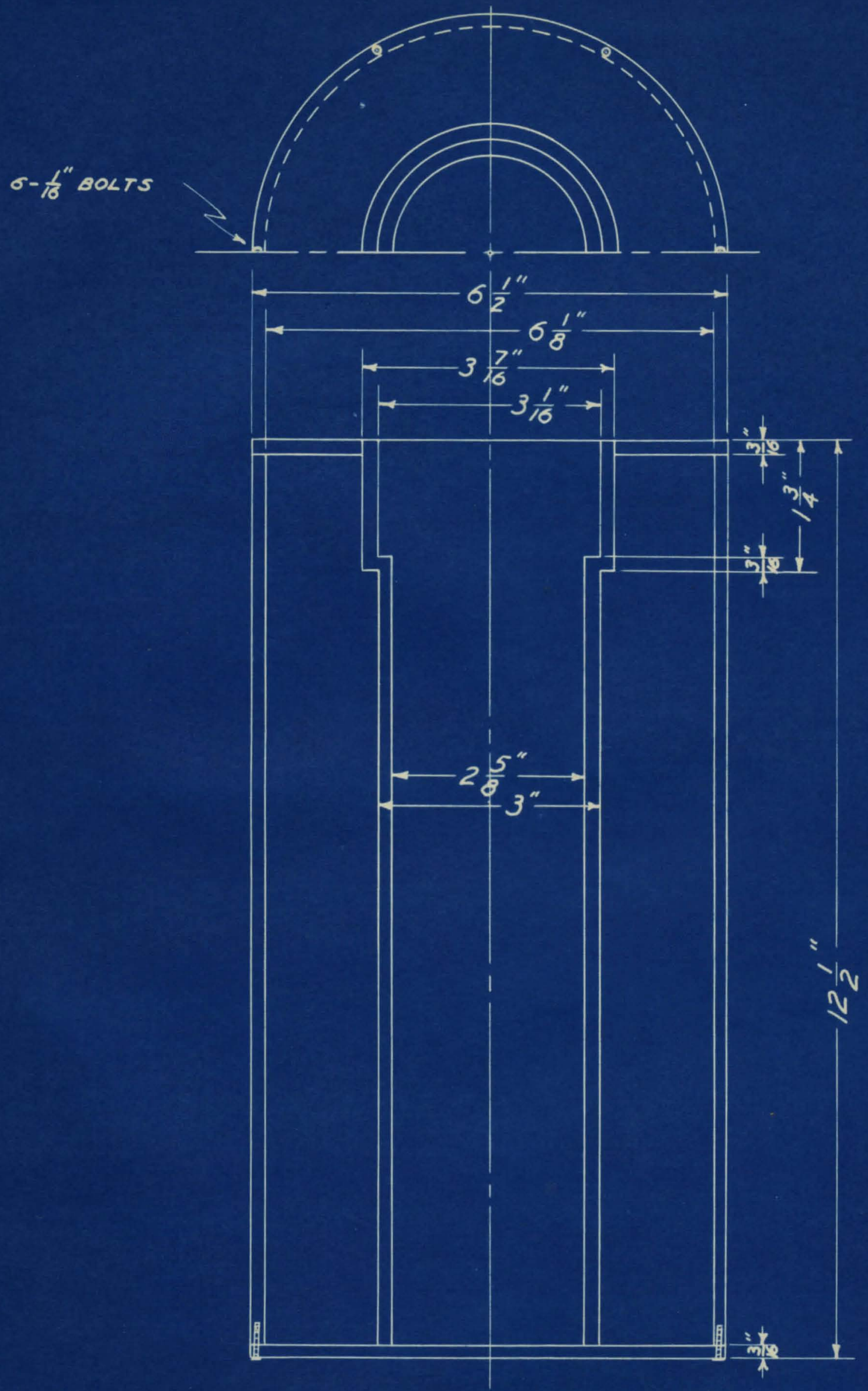

FIGURE II

BOMB CASING 
1. Ansohutz and Sohultz, A Diotionary of Applied Chemistry, Thorpe, pp. 172-4, Vol. IV, Iond on, 1917. (Original Referenoe: Annalen 1879, 196$).$

2. Bracken, Haster's Thes18, Univorsity of Ioulaville, 1940.

3. Chowdbury and Saboor, Oxidation of Hyrocarbons in the Vapor Phase. I. Aromatio Hydrooarbone, Journal Indian Chom. Soo.. 14, 633-7, 1937.

4. Plttig and Ostermayer, Thorpo, 1.0. (0. K.: Annalon, $1873,266,376)$.

5. G1bbs and Conover, U. S. Patent $1,284,888,1918$.

6. Gotz, thorpe, 1.0., (0. R.: Monatsh., 1902, 23, 27).

7. Graebe, Thorpe, 1.c. (0. R.: Annalen, 1873, 167, 140).

8. Graebe and Arbin, thorpe, 1.0., (Or. R.: Annalen, 1888, 247, 268).

9. Iew1s and G1bbs, U. S. Patent 1,288,431, 1918.

10. Helster, Tuolus, and Runing, Thorpe, 1.0., (Fng. Pat. 19178, 1902).

11. Meyer and spengler, thorpe, 1.c., (0. R.; Ber. 1905, $38,443)$.

12. Sohm1tz, Thorpe, 1.c. (O. R.: Annalen, 1878, 193, 116).

13. Th. S. Zal'kind and V. V. Ko sarov, Journal of Applied Chem1stry (U. S. S. R.), 10, 99-104, 1937.

Abbreviations of the titles of fournala:

Annalen: Annalen der Chemio

Ber.: Berichto der Deutsohen Chemisohen Geselisohaft

Montash: Monatshefte fur Chemie und Verwand te The 1le anderer 1 ssengchatton. 


\section{I I A}

Frank thant Hiller Jr.

The author, son of Frank thant IIIler and Ida Ilae lisiler, was borm on Ootober 4, 1918, at Rutherford, New Jersey. A few years later the family moved to Ioulsvile, Kentucky, whore ho ettended the Ioulsville public sehools. He was graduated from the Loulsville Whale H1gh Sohool in 2936.

In September, 1937, he entered the spoed solontific Sohool of the Unlversity of Iouisville, where he purgued a Lour year course in Chemloal inginearihg. recolving his Bechelor of Chemical hingering degree in June, 1941. He contimed his stadies at the Un1vergity of Isouisvillo for another yoar and in lay. 1942, was granted tho degroo of laster of Chemioal Angineering. 